\title{
The Myth of a State
}

\section{by JACK GOODY*}

ThAт the distinction between myth and history is a tenuous one hardly requires elaborate documentation. Anthropologists have recorded the way in which accounts of the tribal past, recorded in genealogies, change with the organisation of the social groups to which they refer. In Malinowski's phrase, they serve as the 'mythical charters' of the social system. But this is a feature not only of non-literate societies. Nations have each their own version of the events which have influenced them; and what one country sees as a schismatic rebellion from the motherland, another regards as the birth of independence, the very creation of its 'freedom'. Such variations in perspective occur not only between but also within nations, and along the lines of temporal as well as spatial segmentation. Each generation reviews the story of its past, and both the selection and presentation of the 'facts' reveal something not only of the personality of the author but also of the Weltanschaung of the age; indeed, it could hardly be otherwise, personality and social systems being as inextricably linked as they are.

The situation is more or less fluid, depending upon the existence of a tradition of historiography. Those new nations of the world whose cultural tradition was until recently largely, if not entirely, non-literate have more scope than those hampered by years of bureaucracy and the consequent accumulation of paper. Like the originators of the Arthurian legends, they have not only to reinterpret the past, but to create it. In the pages that follow I try to trace some of the steps that led to the renaming of the former British Colony of the Gold Coast after the ancient kingdom of Ghana, which Arab writers record as existing at the end of the first and the beginning of the second millennium A.D., some thousand miles away, on the northern side of the Upper Niger.

The claim that the ancient kingdom of Ghana and the Akan of the present State of Ghana were connected is of recent making. ${ }^{1}$ Between the years 1907 and 191 i, the Rev. W. T. Balmer, M.A., B.D., gave a

* Director, African Studies Centre, University of Cambridge.

1 David Kimble, in his Introduction to A Political History of Ghana, 1850-1928 (Oxford, 1963), was, however, the first to show how early the migration claim was made by Ghanaian writers themselves, e.g. Rev. J. B. Anaman, The Gold Coast Guide (London, I895), who had probably read several European accounts, including A.B. Ellis, The Tshi-Speaking Peoples of the Gold Coast of West Africa (London, 1887). 
series of history lessons on this matter to the students of Mfantsipim School at Cape Coast, an institution which has produced many of the leaders of contemporary Ghana. These lectures formed the basis of his school textbook, A History of the Akan Peoples of the Gold Coast (London, 1925), now in its $15^{\text {th }}$ printing.

Balmer was a European priest with a mission. And this mission carried with it a certain philosophy of history. In his preface he writes that he has studied his predecessors (though he gives no references) and has included what he learnt from local tradition (though he gives no 'texts'). This material is to be sifted so as to exclude all 'chronique scandaleuse' and the subject raised to a 'higher plane' 'to show that there has been a definable purpose at work moulding the career of these people'. If the present actors in the drama could be led to grasp this purpose, 'make it more spiritual and follow it loyally then assuredly there would be a worthy future for them as a nation'. One of the goals of this future was to mould the diverse peoples of the Gold Coast into 'a real unity', and the lessons drawn from history should 'set forth plainly the desirability and worthiness of, and the way to this goal'.

One way of attaining the goal of 'real unity' which Balmer mentions is to establish a common origin for the 'various tribes of the Akan race'. Balmer adopts the view that the Negro peoples entered Africa from the north-east or even 'took their rise in the lands near the river Nile'. Gradually they moved westwards and southwards, either voluntarily in search of food or driven by the pressure of new hordes at their heels. The westerly movement split in the region of Lake Chad and diverged into the various parts of western Africa, pressing on until they reached the shores of the Atlantic.

As far as present-day Ghana is concerned, the first of these peoples to arrive were the ancestors of the Guang speakers near Winneba, whom Balmer imagined to speak a language 'very different from any Akan language'. The Akan themselves (the Fanti, Ashanti, Ahanta, and Akan people in general) he thought of as later immigrants from the ancient Negro kingdom of Ghana, whose name he supposed to have given rise to 'the Guinea Coast', although Delafosse's suggestion that this derived from the Niger town of Jenne seems rather more likely.

The evidence he adduces in support of this statement is as follows. First, there is the similarity between the names 'Ghana' and 'Akan'. 'This by itself', Balmer admits, 'might not be a very strong proof, but when we notice that in all the above names the same sound "an" or "ant" occurs, the probability is strengthened.' Secondly, there exists among the coast peoples a strong tradition of a town named Walata, 
and 'it is on record' that when Europeans first came to the Guinea coast in the fifteenth century and sought permission to trade, they were told to apply to the people of Walata.

The second piece of evidence is hardly substantiated by the various written records from the Niger bend; there is nothing to suggest that the ancient kingdom of Ghana ever extended its sway down to the Guinea coast. As there appears to have been no large centralised organisation over the coastal areas when the Europeans came, but rather a number of small states, and as Ghana itself had long since disappeared, both the original claim and the subsequent interpretation seem a little difficult to understand. As for the resemblances between the names Akan and Ghana, it is one of those vague associations without adequate linguistic backing which have so bedevilled the reconstruction of history in many parts of the world where adequate documentary records are not available. Dr David Tait recently showed what could be done in West Africa by the careful use of linguistic material. ${ }^{1}$ But Balmer's suggestion is merely one of the many made by persons untrained in linguistic science in a desperate attempt to fill the gaps in the written record.

One must conclude that Balmer's evidence for the association of the Akan peoples and ancient Ghana is hardly likely to convince a dispassionate observer. But Balmer was a missionary not only for Christianity but for the unity of the peoples living in the Gold Coast. As he straightforwardly admits, 'he has also not hesitated to intermingle his own thought and interpretation of the chain of events'. He regards the ancient kingdom of Ghana as having broken up partly because its inhabitants 'lost the secret of their unity' through their retention of slavery and partly through the advent of Islam into the Western Sudan. But

the meeting with Europeans on the coast of Guinea is destined to be the most decisive event in the history of the Negro peoples and, if rightly used by them, will enable them to recover once again a position of power and influence among the nations of the earth, not only equal to that which they held in the far-off days of the vanished kingdom of Ghana, but one which will far exceed it in all that is worthy of esteem. The right use of their present opportunity will depend upon their learning how to avoid the fatal cause which ruined them as a people in the past. ${ }^{2}$

Thus for Balmer his 'history' was to carry a positive moral, and essential to this purpose was the linking of the present Akan-speaking peoples to

1 D. Tait, 'History and Social Organisation', in Transactions of the Gold Coast and Togoland Historical Society (Achimota), I, 1955, pp. 193-210.

2 Balmer, History of the Akan Peoples, p. 28. 
the ancient kingdom of Ghana. In suggesting that the evidence for this association which Balmer adduced was objectively quite inadequate, I am not intending to convey that $I$ think he offered it in any overtly insincere way. Nevertheless, it was most convenient for his general moral purpose and he clearly did not require much convincing.

This enterprise was given the blessing of the Hon. G. W. Welman, M.A., the then Secretary for Native Affairs, a lawyer who had himself written an interesting account of the political organisation of the state of Peki. He stresses in his foreword to Balmer's history the fact that it attempts to fit the 'backward and isolated' Akan into a world picture. 'By Mr Balmer's conspectus the Akan people themselves are for the first time enabled to see themselves clearly in relation to mankind in general.' And the establishment of these connexions with the rest of the world leads him to account for their present state by a process of supposed degeneration from past greatness. Welman too believes that history serves. He believes that the Akan have great capacity and that great possibilities lie before them of 'rising in the scale of civilisation', and of ceasing to stagnate in the 'backwater', 'if opportunities are wisely used', wisely used not only by the people themselves but also by members of the 'more advanced race which governs the country'. One way of using opportunities more wisely, he declares, is to pay greater attention to contributions such as Balmer's and less to the local press, which at that time was proving a thorn in the flesh of the Administration.

Thus both the Christian missionary and the administrator thought that history could serve moral ends and that these ends could be forwarded by tracing the connexion between the Akan-speaking peoples and the more developed states of the Niger bend. Balmer sees them relearning the secret of their lost unity, to be regained by adopting the Christian faith, while Welman hopes that they can be encouraged to aim at the higher achievements of their forbears and learn more of European methods.

Balmer's hypothesis of a migration of peoples from the Niger to the Guinea Coast is not in itself absurd. Indeed, the ruling class of the state of Gonja in the Ashanti hinterland claims to have migrated in just such a way within the last $35^{\circ}$ years. What is dubious is, first, the method of proof and, second, the assumption of 'total migrations'. The same methods and the same assumptions have been used to prove quite different theories about the origin not only of the Akan but of other West African peoples as well. Indeed, these earlier theories on the subject form a fascinating chapter of the story of Ethnological Extravaganzas or Crackpot Anthropology. 


\section{BOWDIGH AND THE EGYPTIANS}

The first of these theories to be propounded with any degree of documentation was in An Essay on the Superstitions, Customs, and Arts, Common to the Ancient Egyptians, Abyssinians and Ashantees (Paris, 1821), by T. Edward Bowdich, who describes himself on the title-page as Conductor of the Mission to Ashantee and Member of the Wetteravian Society. In his well-known account of his mission to the court of the Ashanti ruler at Kumasi, Bowdich had already given us by far the best account, up to that time, of any West African people $;^{1}$ and his book, although bitterly criticised by his successor, R. Dupuis, is full of interesting information and penetrating observations. The Essay is by no means an unscholarly work; indeed, one of the characteristics of this school is the thoroughness with which they pillage their resources and encompass an immense learning into multitudinous footnotes.

Bowdich begins soberly enough:

The traditions of emigration, not of the whole population but of particular families, so current in Ashantee and the neighbouring nations, the numerous exceptions to the negro countenance, and the striking similitude of most of their more extraordinary superstitions, laws, and customs to those of ancient Egypt, persuade me that most of the higher classes are descended from eastern Ethiopians who had been improved by intercourse with the Egyptian emigrants and colonists. ${ }^{2}$

At least, then, Bowdich does not make the assumption of a 'total migration'. And it was not unnatural that the customs of any newly discovered territory should be compared with the Middle East, for this was one of the only areas of non-European culture known to educated persons of the western world. The real trouble with such comparisons is not so much that they were false as that they apply to such a large number of non-European societies in all parts of the world; and there seems little reason to suppose that all such customs were emanations from Egypt. Either they formed part of a common tradition of unknown origin (as Frankfort suggests in a rather limited context for the certain likenesses between Egypt and East Africa); or alternatively they may be considered as similar responses to similar cultural situations. Whatever the cause, societies have much in common. Striking similarities such as the Ashanti and Abyssinian practice of swearing on the king's head led Bowdich to assume a migration of peoples, whereas increasing knowledge about kingship in a comparative perspective shows that other explanations are possible.

1 T. E. Bowdich, Mission from Cape Coast Castle to Ashantee (London, 1819). 2 Ibid. p. 5 . 
But he claimed to have found more specific similarities than these, namely in language, a field in which the purveyors of Intuitive Ethnohistory really come into their own. He discovers similarities between the Ethiopian title ozouri and the Ashanti oura, between the names of Ethiopian provinces (e.g. Hauasa, Cont, Gan) with the names of West African kingdoms (Houssa, Kong, Gana), and between the names of the kings of Ethiopia (Aiba, Bakr, Armah) and the rulers of Ashantee (Ayboo, Bakki, Arma).

Unlike most of his successors, Bowdich appears to have had no obvious axe to grind in suggesting this theory. It occurred to him as a result of noting the real similarities between the customs of the Ashanti and of those parts of north-eastern Africa about which he had read. And it was pursued out of pure scientific curiosity. 'Much light', he concludes, 'may be reflected on Antiquity, as well as Natural History and the Physical Sciences, by pursuing our discoveries in Africa, gradually, and in detail.'1

This detachment was not characteristic of all that vast school of migrationists who have traced the diffusion of each and every aspect of human culture from the various countries of the Middle East to the four corners of the globe. Churchmen, for example, have been zealous in propagating hypotheses concerning the dispersion of the Jews, apparently receiving support from the idea that if an Indian tribe returned home victorious, singing a triumphant song to Yo-HE-WAH (that is, Jehovah), they would be all the more likely to accept Christianity. Moreover the idea of bringing stray members of the flock back to the fold has a strong moral appeal both to the itinerant shepherd and to those at home who provide his funds. The case to which I have just referred is taken from Mrs B. A. Simon's The Hope of Israel: presumptive evidence that the aborigines of the western hemisphere are descended from the ten missing tribes of Israel (London, I829), a book in which the missionary element is much to the fore. There are, of course, few parts of the world where the ten tribes have not been identified, and the existence of this myth has led to its elaboration in breakaway sects such as the Church of the Latter Day Saints.

The hypothesis of a Hebrew migration to West Africa was not developed in detail until some roo years later, in a book called Hebrewisms of West Africa (London, r930), by a Catholic missionary, Father J. J. Williams, S. J., Ph.D., Litt.D. When Bowdich was writing, little was known about the countries which lay between the Middle East and West Africa, and he does not say much about the mechanics of the migration itself. However, Father Williams is much more specific here

1 Ibid. pp. 18, 40-I, and 63 . 
and is able to suggest a precise route, beginning, according to him, from Jerusalem, taking in Meroe, Kordofan, Lake Chad, Kano, Gao, and the Northern Territories on the way, and eventually landing up in Ashanti. His source of Ashanti culture is Hebraic rather than EthiopianEgyptian, and his hypothesis runs as follows:

We feel safe then, in formulating our first conclusion: Somewhere in the dim past, a wave, or more probably a series of waves, of Hebraic influence swept over Negro Africa, leaving unmistakable traces among the various tribes, where they have endured even to the present day.

This is demonstrated, as we have seen, by such culture elements among the Ashanti as the $\mathrm{Ob}$ cult; religious dances; use of 'Amen'; vowel value; patriarchal system; parallel symbolism of authority in 'stool' and 'chair'; endogamy; cross-cousin marriages; familial names; exogamy; simplicity of marriage rite; uncleanness after childbirth; purification ceremonies; menstrual seclusion; ceremonial ablutions; and Ashanti loan words of apparent Hebrew origin. Then in matters of religion, we have the truly remarkable similarity of the Ashanti Yame and the Hebrew Yahweh. ${ }^{1}$

Here again proof is supplied partly by linguistic resemblances, but principally by a selection of cultural traits, some of which provide genuine cases of similarity, though one would hardly have thought that Ashanti was noted for its 'patriarchal system' and the inclusion of both endogamy and exogamy appears to be a classic instance of 'having it both ways'. The trouble is that 'traits' such as exogamy and ritual uncleanliness are virtually universal. Bowdich's suppositions on this score may be in part attributed to the lack of available knowledge; in Father Williams's case, the material was overlooked. Both authors have been struck by the similarities between the ancient Middle East and West Africa, which they have come across in their reading. But, whereas Bowdich derives all culture from Egypt and thus paves the way for G. Elliot Smith's In the Beginning (New York, 1928), and W. J. Perry's Children of the Sun (London, 1923), Father Williams follows Mrs Simon, Joseph Smith (founder of the Mormons), and the British Israelites in regarding Israel as the source of light. In both cases they account for the striking similarities perceived by the only theoretical tool at their disposal, a conjecture of diffusion by migration, known to its protagonists as the historical method and to its critics as pseudo-history. While Bowdich has no specific interest in such a proposal, Father Williams, like Mrs Simon, recognises that the task of missionaries is simpler if they are engaged in reawakening a primitive concept of monotheism. Moreover, they are helping the fallen to stand once more on their feet. Just as the Jews of the Dispersion were said to form the bridge across

\footnotetext{
1 Williams, Hebrewisms of West Africa, pp. 319-20.
} 
which Christianity entered the Roman World, so the Diaspora of the Chosen People of God in West Africa was, according to Father Williams, to 'pave the way for Christianity'.

Although Bowdich and Williams mentioned the ancient Niger kingdom of Ghana, neither gave it any special weight in the migrations from the Middle East to Ashanti. They both saw the Mediterranean influence as coming from the Sudan via Lake Chad, a route which does not pass through the countries of the upper Niger. Williams's route map, for example, by-passes the whole of that area.

\section{DANQUAH, MEYEROWITZ, AND ANGIENT GHANA}

The hypothesis of the migration of the Akan from ancient Ghana to the present Ghana, originally propounded by Balmer, was developed by $\operatorname{Dr}$ J. B. Danquah, who subsequently became one of the foremost leaders in the nationalist movement up to the time of the formation of the Convention People's Party by Kwame Nkrumah. Dr Danquah had read the details of the ancient state of Ghana, supplied by medieval Islamic scribes and translated by the French, in an English account entitled $A$ Tropical Dependency (London, 1905), the author of which was Flora Shaw, wife of Lord Lugard, the famous Governor of Nigeria whose name is associated with the development of administration by Indirect Rule. Struck by the similarities there described and the customs of the Akan-speaking peoples, Danquah adopted the idea of a migration in The Akan Doctrine of God (London, 1944). Although the book itself is dedicated to expounding the value and complexity of the indigenous pre-European ideas of the Deity, and to showing that 'the Spirit of God is abroad, even in the Akan of the Gold Coast', in an appendix he writes of Ghana as an Arab corruption of Akane or Akana, and suggests that these should be identified with the 'old Babylonian race known as Akkad'.

The most thoroughgoing development of the theory of migration is put forward in the works of Mrs Eva L. R. Meyerowitz, who has now completed four volumes on the Akan of Ghana. ${ }^{1}$ She declares $\mathrm{Dr}$ Danquah to be the inspirer of her researches, and he on his part has applauded her discovery of the connexions with the 'ancient heliolithic cultures which once flourished in the Mediterranean and the Ancient East'.2 Mrs Meyerowitz attempts for the first time to analyse in detail

1 E. L. R. Meyerowitz, The Sacred State of the Akan (London, 1951), Akan Traditions of "Origin (London, 1952), The Akan of Ghana: their ancient beliefs (London, 1958), and The Divine Kingship in Ghana and Ancient Egypt (London, 1960).

${ }^{2}$ J. B. Danquah, 'The Culture of the Akan': in Africa (London), xxII, 1952, p. 360. 
the stories of migration, many of which she had collected. Her conclusion is that 'the Akan people... came originally from the region between Djenne and Timbuktu, and from some places further north in the Sahara desert. One can safely deduce...that the ancestors of the present Akan aristocracy were Saharan Libyan Berbers.' ${ }^{2}$ She even pinpoints the exact location, the oasis of Jado or Djado in the desert west of the Sahara, linked with the name Dia, a word to which she attaches great significance in the Ashanti migration stories.

The methods employed by Mrs Meyerowitz have been criticised by R. Mauny, Tait, and myself; there is no point in dwelling on this here. Suffice it to say that they are similar to those of Bowdich, Williams, and Danquah, with the addition of an interpretation of migration stories which she and her assistant, the late Kofi Antubam, collected. Unfortunately the original texts are not given, and there is some reason to feel uneasy about these renderings of them. ${ }^{2}$

In the main body of her work, Mrs Meyerowitz pays little attention to the hypothesis that the Akan came from Ghana, but the proclamation of the new state led her to a special consideration of this point. ${ }^{3}$ By a somewhat astounding stroke of the pen, she transmutes the Mandespeaking Sarakole (Soninke), believed to have formed the basis of the population of Ghana, into the Diara-Kore, since 'in other regions in the western Sudan the name would be' of this form. The author has already isolated by similar methods three 'basic ethnic elements' among the founders of the Akan states, namely: ' (a) Dia (or Za, Diaga, Zaga, Zara, etc.), the descendants of people who in Africa appeared first in Ethiopia (Abyssinia) at the beginning of our era; (b) Guan (Gwan or Wan, whose Saharan name was Ilanguantan, Agwatin, etc.), Saharan Libyan Berbers; (c) Gara (Kora or So, etc.), Saharan peoples of Kushitic stock'. These she is able to identify with the Diara, Kore, etc., whom she has already perceived in the word 'Sarakole', and therefore concludes that the facts 'strongly suggest' that the founders of Ghana and the Akan states included these same non-negro elements, though the facts of physical anthropology force her to assume that 'by intermarrying with negro aboriginals in the western Sudan, [they] underwent considerable racial modifications and admixtures'.4 Thus the connexions between Ghana and the Akan-speaking peoples through the common ethnic origin of their founders, though placed on a different basis from the straightforward migration of Balmer and

1 Akan Traditions of Origin, p. 124.

2 See J. R. Goody, 'Ethnohistory and the Akan of Ghana', in Africa, xxIx, I, 1959.

3 Meyerowitz, 'The Akan and Ghana', in Man (London), LvIr, 1957.

4 Ibid. pp. 86-7. 
Danquah, are once again re-established, even though the negro aboriginals recede further into the interstices of history. Indeed even their culture vanishes, for in her latest volume Mrs Meyerowitz concludes that 'Akan culture and civilisation is not Negro-African in origin but can be classed, on the whole, as Libyo-Berber, more precisely perhaps as Libyo-Phoenician or Carthaginian. . . a civilization which owed almost everything to the Near East and Egypt.'

Thus the matrilineally organised Akan belong to the same 'Kultur Kreis' as the ancient peoples of the East, so that 'their concept of State, their religious beliefs and customs give us clues to the world of the ancients which archaeology alone cannot provide.'1

The wheel has come full circle; we are back to Bowdich, the Ancient Egyptians, yes, and even the Abyssinians. The 'evidence' has multiplied, but its quality has changed little, and the method of seeking linguistic and cultural similarities has remained the same. Moreover, the activity has remained the preserve of the amateur linguist and anthropologist rather than the professional-this in fields where even the work of professionals gives cause for alarm. Indeed, there have been those among them who have espoused similar theories of mass cultural diffusion from the Middle East-Elliot Smith, Rivers, and Perry, with their 'children of the sun' spreading light into the dark corners of the world ${ }^{2}$-or Meinhof, ${ }^{3}$ Seligman, and others with the Hamitic theory. A recently revised edition of Seligman's little book, Races of Africa, still maintains that the Hamites 'were, in fact, the greatest civilising force of black Africa from a relatively early period'.4

When we consider these hypotheses of diffusion, we must separate the spread of cultures from the spread of peoples. As far as the spread of peoples is concerned, there is little evidence of such a mass migration of non-Negroes into Negro Africa. West Africa has been inhabited for a very long stretch of time. Recent research in Ghana has claimed to find evidence of the pebble culture of the Lower Pleistocene, considerably before man appeared in Europe. There is still some controversy as to whether the pebble tools of East and West Africa are in fact human artifacts. But, apart from this, a Chellean site has been discovered and a great deal of Sangoan material is found. Occupation was certainly intermittent, and man may have been forced out of the area by the pluvials and the droughts; but Dr O. Davies claims that

1 The Akan of Ghana, p. I 5 .

2 See Elliot Smith, In the Beginning; W. J. Rivers, The History of Melanesian Society (Cambridge, I914); and Perry, Children of the Sun.

3 C. Meinhof, An Introduction to the Study of African Languages (London, 1915).

4 C. G. Seligman, Races of Africa (London, I957 edn), p. Io. 
since the last dry period, perhaps I5,000 years ago, man 'seems to have continuously occupied West Africa'.1

As no human remains have been found associated with these earlier archaeological discoveries, we cannot say whether the human beings who have been living here so long were Negro or whether they belonged to some other group. The existence of Negroes in the Pacific area has given rise to the suggestion that they entered Africa from the northeast; the evidence for this lies mainly in the absence of negroid skulls among the early skeletal material of East Africa. If this hypothesis is correct, then the spread of Negro peoples is not a recent occurrence, for Negro captives are portrayed on one of the great Egyptian protodynastic palettes dating from c. 3,200 B.c. ${ }^{2}$

No trace of any other race has been discovered in Ghana. It has been suggested that the sorties of mmoatia, or little folk, indicate an earlier occupation by the pigmy peoples or negrilloes; but there is as little reason to believe this as to believe that the European fairy testifies to the existence of an ancient race. For both West Africa and Europe there is, I think, a sociological explanation for the existence of the belief. In any case, physical anthropologists consider the negrilloes to be a subdivision of the negroid race.

We may therefore legitimately conclude both that Ghana has been occupied for a very considerable period and that the Negro occupation of that area has been a long one. Moreover, of all the inhabitants of Africa, Seligman chooses the speakers of the Kwa languages, of which Akan is a subgroup, as typifying the 'true Negro' both from the cultural and from the physical point of view. And of these he particularly singles out the Akan-speaking Ashanti as being protected from intermixture and, basing himself on Rattray's measurements, describes them as being 'characteristic of the true Negro stock' ${ }^{3}$

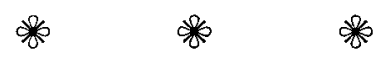

The relatively recent hypothesis of a mass migration from ancient Ghana or elsewhere seems therefore unacceptable from the standpoint of physical anthropology. Let us consider the possibility of cultural change on a massive scale, which is suggested, I submit, by all these authors, though by some more directly than by others. Change would result not from a mass migration of peoples, for the facts of physical anthropology appear to discount this, but from a movement of a small

1 O. Davies, 'Earliest Man, and how he reached Ghana', in Universitas (Legon), March $195^{8}$, p. 36 .

${ }^{2}$ Seligman, op. cit. p. $4^{2}$.

3 Ibid. p. $5^{8 .}$ 
number of peoples, making temporary contact by way of trade or permanent contact by immigration. I believe there is no evidence of a massive importation of culture from outside in the case of the Akanspeaking peoples. It seems probable that various crops, metal-working, and other cultural features have crossed the Sahara from north to south. But such features are widely diffused throughout Africa and there is no special case to be made out for the Akan. The culture of the Ashanti and other Akan-speaking peoples can in all major respects be paralleled among other Negro peoples. Most, if not all, of the features mentioned by these writers have been selected as indices of diffusion. That is not to deny the similarities between the culture of the Akan and that of the ancient inhabitants of the Middle East. But such similarities are world-wide, and require explanations of a different kind. ${ }^{1}$ The culture, like the language, of the Akan is characteristically West African and cannot be singled out for special treatment.

To reject mass migration or large-scale cultural diffusion for the Akan is not to reject them for Negro Africa as a whole; undoubtedly such movements have taken place in the distant past, and archaeological evidence will lead to the development of more substantial hypotheses about the prehistory of West Africa. But there is no case to be made out for such happenings influencing the Akan alone. Undoubtedly the Ghana of the present day had contacts with the medieval kingdoms of the Niger bend; some of the positive evidence of this has been collected in my account of the Ashanti hinterland. ${ }^{2}$ Future research will doubtless be able to show what cultural feature came along this route; and there is already some evidence for the movement of peoples. But there is nothing whatsoever to suggest that the 'Akan' as such came from the north. For who are the Akan but the present-day speakers of a certain group of languages which, like their culture, belongs firmly to West Africa?

We do not then reject the long-standing connexions between presentday Ghana and the states of the Niger bend-of which ancient Ghana was one of the earliest-nor yet, given the present archaeological evidence concerning the beginnings of agriculture, the further connexion with the Middle East, although this connexion would be true of all the food-producing communities in Africa. What we reject is, first, the methods used to establish such connexion and, second, the idea of a mass migration or massive diffusion between the two.

1 Gf. J. R. Goody, 'Death and Social Control among the LoDagaa', in Man, LIx, 1959, p. 204.

${ }^{2}$ J. R. Goody, 'The Ethnology of the Northern Territories of the Gold Coast west of the White Volta' (London, Colonial Office, 1954, mimeo.). 
Yet this hypothesis, developed in just such a manner, has now become the accepted dogma of a nation. Dr Danquah himself was a leading member of the campaign for independence in the years following World War II and, partly through him, the Ghana theory became an established part of nationalist ideology. Private schools were named Ghana Colleges, the motto 'Ghana Boy' was painted above the cabins of innumerable mammy lorries, and the more 'conservative' political party which emerged in opposition to Nkrumah's Convention People's Party adopted the title Ghana Congress Party. To the populace the use of the term meant a rejection of the colonial status implied by 'the Gold Coast'.

The appeal to nationalist aspirations was not essentially dissimilar from the appeal of the Rev. Balmer and the Secretary for Native Affairs. The association with the old kingdom of Ghana meant a connexion with an established civilisation, which at the time of its zenith was in many ways the equal of the contemporary kingdoms of Western Europe. And behind the link with Ghana was a shadowy association with the ancient Middle East, the very source of the urban civilisation of the west. The claim of the Akan to be connected with the cultures of the Fertile Crescent is similar in kind to that made by the Arthurian legends, which associated a newly established ruling class of England not only with the indigenous Celtic traditions but also, through the Grail legend, with Christian mythology, as well as with the ancient societies of the Mediterranean world. Indeed the name of Brute still adorns some of the more fanciful pedigrees of the House of Windsor. As in Polynesia, the depth of the genealogy is in itself a legitimisation of a claim to office.

What is true of dynasties also applies to nations. The adoption of the name of an ancient kingdom legitimises the status of a newly founded nation, one whose present boundaries did not exist prior to the establishment of a colonial government. The process of writing the mythhistory not only provides a justification for its existence as a separate unit, a justification which the earlier pan-Africanists would have deplored; it also serves to create the nation and, by supplying a focal point, similar in kind to the flag, the anthem, and the other ritual trappings of a modern state, to crystallise attitudes both within and without the community. In this way the specific myths of new states contribute to both the unity of nations and the disunity of the continent. 